\title{
Effective Traffic Management System By Using Hydraulic Footpath
}

\author{
Prof. Chetan N. Gawali"1, Amit R. Bhongade'2, Amit M. Ramteke ${ }^{3}$, Nilesh G. Landge ${ }^{4}$, \\ Prafull P. Shende ${ }^{5}$, Sagar S. Modak \\ ${ }^{*}$ Assitant Professor of Civil Engineering, Nagpur Institute of Techonolgy, Nagpur, Maharashtra, India \\ 2-6UG Student of Civil Engineering, Nagpur Institute of Techonolgy, Nagpur, Maharashtra, India
}

\begin{abstract}
Vehicular traffic is the major problem in metropolitan cities because traffic congestion is increasing rapidly at signalized intersections; it results in chronic situation in dense downtown areas. Traffic congestion is also major problem for smooth transportation. So, here we adopted a mechanism which minimizes traffic problems and that mechanism is called hydraulic machine. Hydraulic machine is the mechanisms which lift the things up and down at a particular height. Our purpose is to create a mechanism which lifts the footpath at signalized intersection up and down when there is more traffic at signalized intersection. We studied about the various congested signalized intersection areas and then selected Bhim Square for our study. We collected the peak hour traffic data using videography survey method and categorized the vehicles into different classes. Calculate the queue length at bhim square using normal footpath and again calculate the queue length for same traffic data by using hydraulic foothpath. On comparing the reduction of queue length percentage we observed that hydraulic footpath is more preferable than the normal footpath for congested traffic at signalized intersection, because it reduce approximate $60 \%$ queue length. Also, hydraulic footpath gives extra space at signalized intersection and it helps to increase service volume.
\end{abstract}

Keywords : Vehicular traffic, Bhim Square, ITDP, IRC

\section{INTRODUCTION}

\subsection{TRAFFIC CONDITION IN INDIA:}

As you know that the India is second largest population country in the world also India is a second largest road network in the word and first largest road network is United States of America (USA). According to rank in Indian roads is $5903293 \mathrm{~km}$ and expressway is $1583 \mathrm{~km}$. According to annual report 2017-18-ministry of road transport and highways government of India.it is also a big challenge or huge challenge to maintenance of roads every year \& every decade. The reason to maintenance of roads is to increase of private vehicle \& overburdening of roads in all big cities or major cities of the country. Most of the cities are suffering from medium to high level of traffic congestion like Nagpur, Mumbai and Delhi etc. The poor roadway condition, non-uniform roadway affects the poor lane discipline, improper bus stop location and design, vehicles of wide ranging characteristics and operating condition, uncontrolled on-street parking, etc.

As you know that most of the Indian youth owing is own car \& two- wheeler \& this is big problem to increases pollution \& bad or rash drivers in India. The person spends 30 minutes to 2 hours of their day driving. That means it about 360 hours in a year. In India already full of existing lifestyle \& related 
diseases \& the driving \& tariffing. Creating unnecessary addition problem in India. In India some of the major traffic problem in India is facing today. Traffic congestion in India is a major problem for transportation. Its indicate that the nature and cause of congestion in India that.

\subsection{TRAFFIC CONDITION IN NAGPUR CITY:}

Generally Traffic is defined as the movement of a person vehicles or any type of goods or person in between the site locations, and includes pedestrians and all types of vehicle. Traffic condition which is day by day leading a severe or worst problem of Nagpur city. In Nagpur city heterogeneous traffic conditions. Nagpur is at present third largest city in Maharashtra which faces traffic congestion problems mostly in the different road intersection. In Nagpur rapidly, increasing population day by day. This used to reduce congestion on the particular intersections the Bus Bay is to be provided for the city buses moving on the particular section. The Noise pollution, congestions and air pollution and the results in ill effects to the health. In this analysis respectively increase in demand for survey is to be taken for vehicle count and analysis is done to increase future development of transport network in nagpur city.

\subsection{TRAFFIC CONDITION AT SIGNALISED INTERSECTION:}

Transportation is carrying civilization to a brighter future. Currently transportation is one of the most valuable problem in every area of the world. Every country try to resolve transportation issues as per the capability and resources. The traffic volume are steady. Traffic volume is simply the number of vehicle passing a section of a roadway during specified unit of time. In signal number of vehicle are staying one line back to back is known as queue, and their distance between first to last vehicle of the length is known as queue length.

\subsection{PEDESTRIAN TRAFFIC AT INTERSECTION:}

The definition of a pedestrian is a person who is walking along a road or some development area to get where he needs to go. The traditional way of designing public transfer station is based on rules of thumb. There rules deliver experience about the behavior of passenger in transfer station. However, they only consider constant or still situation. Different type of pedestrian such as elderly people or parents with children needs different transfer time. The factor affecting the walking speed of pedestrian age, gender, size, health, etc. characteristics of the trip walking purpose trip length. The walking speed also depend on the pedestrian volume.

\subsection{FOOTPATH:}

A foothpath is the part of road or other public place that is laid out or built for pedestrian use. According to WHO (World Health organization 2013): The pedestrian or footpath is also defined as the pedestrian is any person who is travelling by walking for at least part of her journey. The benefits of walking it helps to economics, Environmental, social and health benefits. All of these benefits lead to a better quality of life for people. Footpath are a publicly good and are always provide by the government. In urban life walking is fundamental part in India also walking is a healthy and pollution free from of mobility.

As per the institute for transportation and development policy (ITDP)'s reference guide and the Indian road Congress (IRC)-2012 guidelines in India $1.8 \mathrm{M}$ wide enough for residential areas for two wheelchair and for commercial zones it is $2.5 \mathrm{M}$ wide and a ideal height is $150 \mathrm{~mm}$ As per the design of footpath needs to a flat walking surface and walking 
zones should be clear of all obstruction including poles, utility ducts and electricity.

In India it is clear that pedestrian in India cities currently have the lowest priority for walking in footpath.

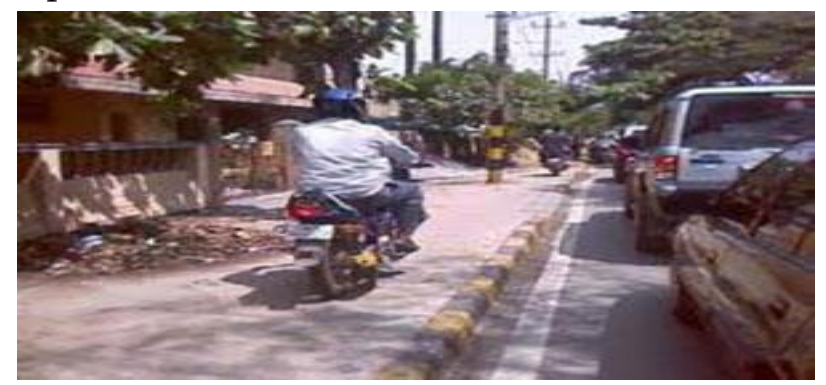

Fig.1

\subsection{HYDRAULIC MACHINE:}

The word hydraulics is based on water, originally covered the study of the physical behavior of water at rest and in motion. Hydraulics includes different types of manner or style in which liquids act in tanks and pipes, deals with their properties, and explores or find out the ways to take advantage or benefit of these properties. Although the modern development of hydraulics has many principles and their applications. Hydraulic jack is based on the Pascal's law which states that increase in pressure on the surface of a confined fluid is transmitted undiminished throughout the confined vessel or system.

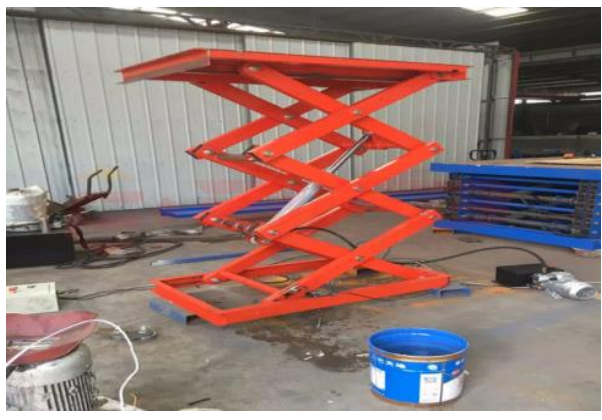

Fig. Hydraulic Machine

\subsection{OBJECTIVES:}

1.To minimize the formation of platoons at signalised Intersection.
2.To manage both pedestrian traffic and vehicular traffic at signalised intersection by using hydraulic footpath.

3.To provide extra space for manoeuvring the traffic in emergency situation.

4.To increase service rate of signalised intersection by using hydraulic footpath.

5.To reduce Queue length at signalised intersection.

\subsection{NEED OF STUDY:}

We observed that vehicular traffic is very high at bhim square and queues are formed in peak hours so, that minimization of queue is the demand. In incidental and accidental situation there is no alternate way to divert the traffic from current road to other road.

\section{METHODOLOGY}

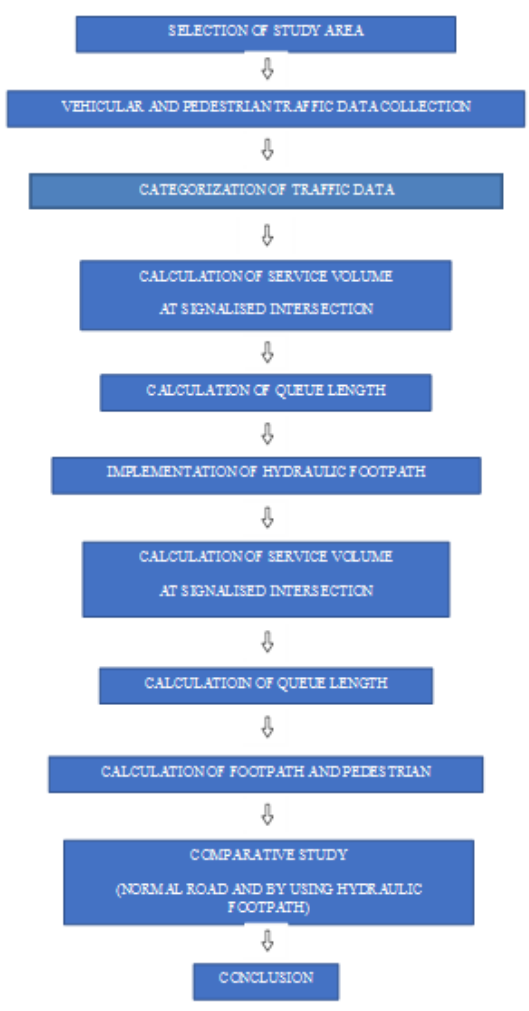




\subsection{Study Area and Data Collection:}

To provide hydraulic footpath we have selected such a site where there is a junction of 4 roads where consist footpath by the all sides of road. There are many such intersections in our city from which we have selected "Bhim Square".

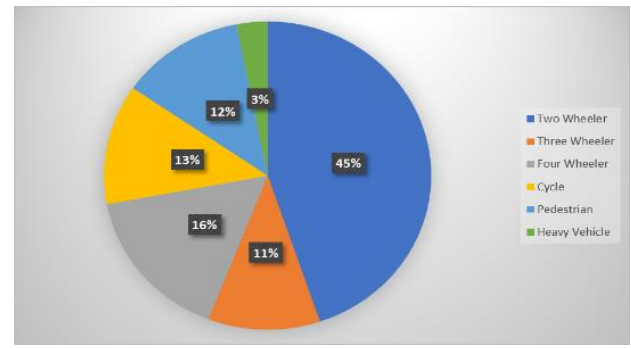

(c) Wednesday:

\subsubsection{Study Area:}

Place: Nagpur

Area: Bhim Square

Latitude and longitude: $\mathrm{NL}=21^{\circ} 10^{\prime} 59^{\prime \prime} \mathrm{EL}=79^{\circ} 05^{\prime} 36^{\prime \prime}$
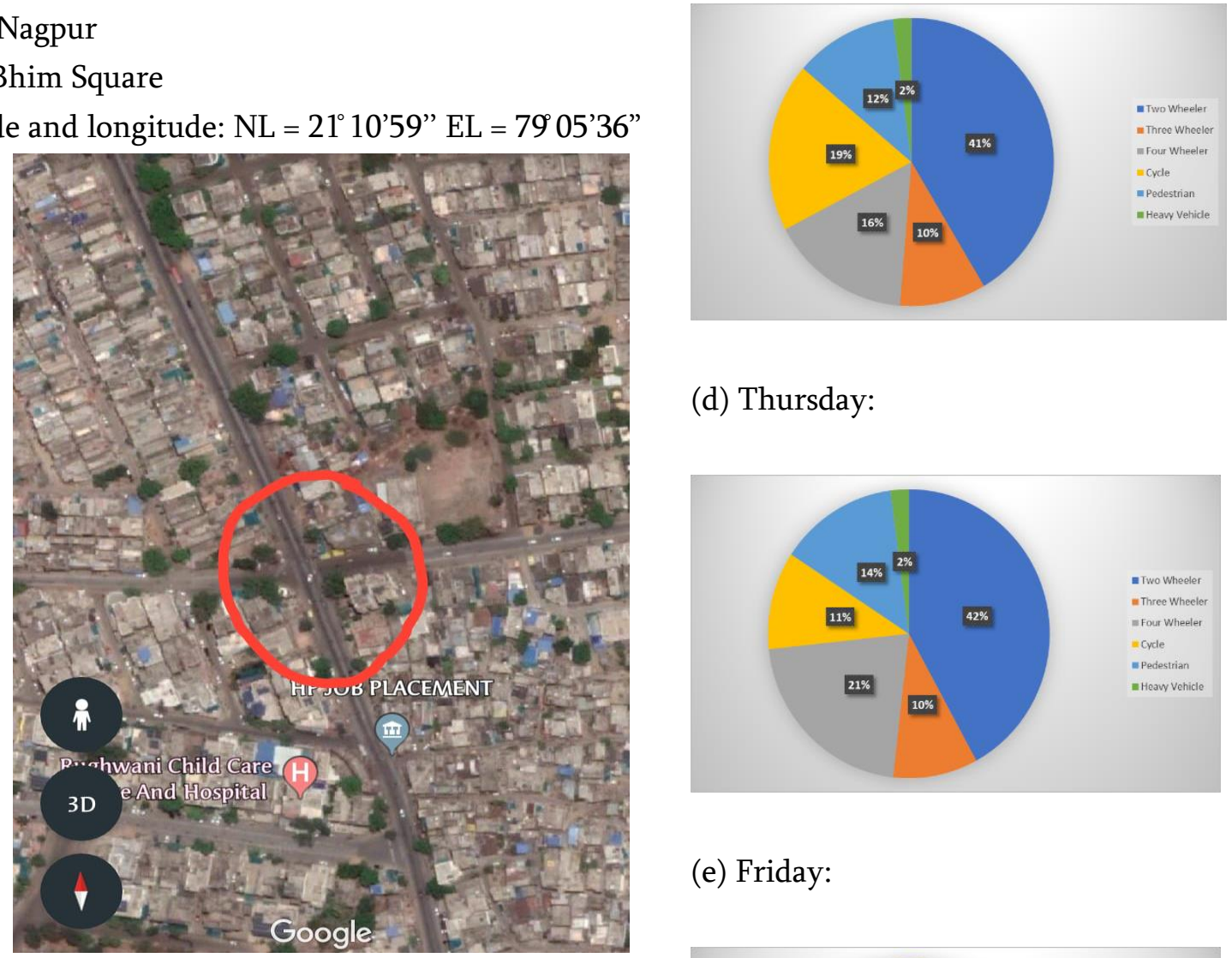

(d) Thursday:

\subsection{Data Collection Of One Week on Bhim Square:}

(a) Monday:

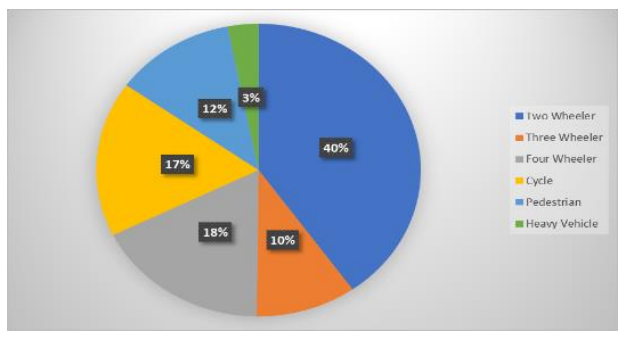

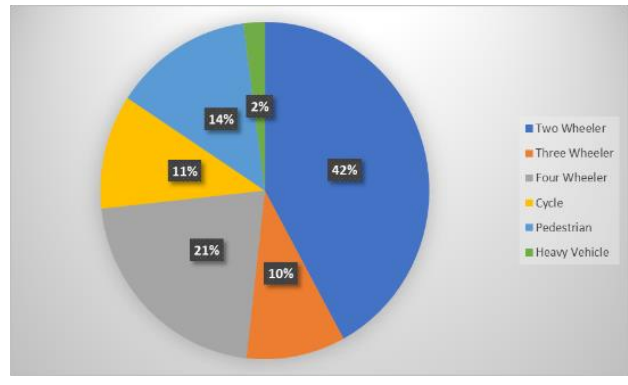

(e) Friday:

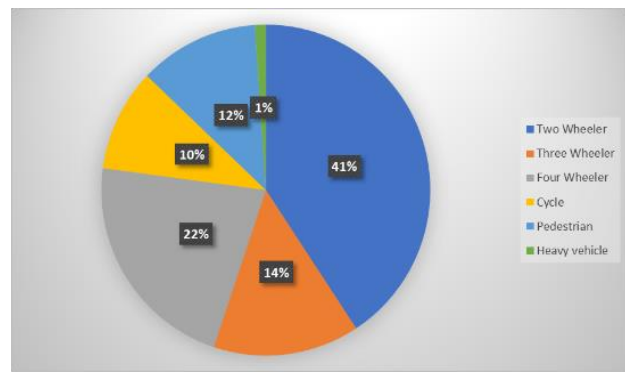

(f) Saturday:

(b) Tuesday: 


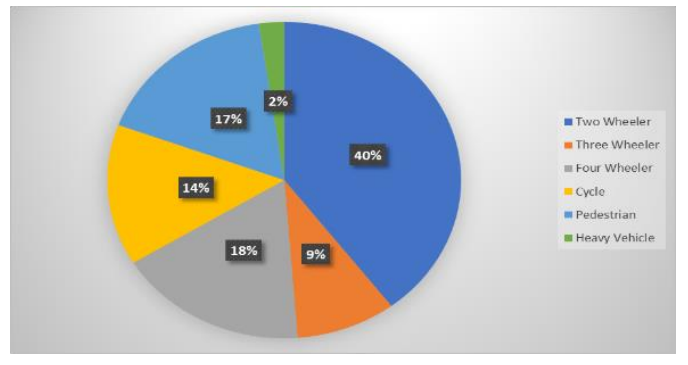

(g) Sunday:

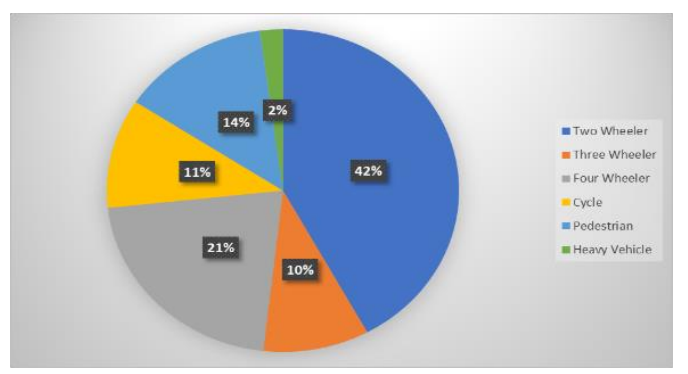

\subsection{CALCULATION OF CURRENT ROAD:}

3.3.1 Calculation for service volume at signalized intersection:

-Service volume at $6.2 \mathrm{~m}$ width of road:

- Width of road $=6.2 \mathrm{~m}$

- Load factor $=0.3$ ...(ref. from HCM 2000)

- Population for city = 24 lakh

- Peak hour factor:

$\mathrm{PHF}=V / 4 \times \mathrm{V} 15=4400 / 4 \times 1140=0.96$

- Hourly Volume $=4400 \mathrm{v} / \mathrm{hr}$. ...(from nomograph chart)

- Peak hour factor $=1.21$

$-\mathrm{G} / \mathrm{C}$ ratio $=31 / 119=0.26$

Therefore, service volume $=$ Vehicle volume per hour $\times$

Adjustment factor $x$

Peak hour factor $x$

$G / C$ ratio

$=4400 \times 1.25 \times 1.21 \times 0.26$

$=1730 \mathrm{VPH}$

\subsubsection{Calculation for Queue length:}

- Formulas for Queue Length:

- $\mathrm{Q}=t_{Q} \times Q m / 2 c$

- $Q_{m}=\mathrm{V} \times r / 3600$

- $t_{Q}=\left(\mathrm{C}-C_{R}\right) \times t / C-V$

Where,

$$
\begin{aligned}
& \mathrm{V}=\text { Mean arrival rate (veh/hr) } \\
& \mathrm{r}=\text { Effective red time (s) } \\
& \mathrm{Q}=\text { Average Queue length (veh) } \\
& Q_{m}=\text { Maximum queue length (veh) } \\
& C_{R}=\text { Mean service rate (veh/hr) } \\
& \mathrm{C}=\text { Mean service volume (veh/hr) } \\
& \mathrm{c}=\text { Cycle length (sec) } \\
& t_{Q}=\text { Time duration of queue }(\mathrm{sec}) \\
& \mathrm{t}=\text { Effective red time }(\mathrm{sec})
\end{aligned}
$$

1) Nara Road:

- Service Volume $=1466 \mathrm{VPH}$

- Service Rate $=1026 \mathrm{VPH}$

- Arrival Rate $=1320 \mathrm{VPH}$

$$
\begin{aligned}
t_{Q}=(\mathrm{C}- & \left.C_{R}\right) \times t /(C-V) \\
= & (1466-1026) \times 0.0234 / 1466 \\
= & 0.0705 \mathrm{hr} . \\
= & 254 \mathrm{sec} .
\end{aligned}
$$

$$
\begin{aligned}
Q_{m} & =\mathrm{V} \times r / 3600 \\
& =1320 \times 84 / 3600 \\
& =31 \text { veh } .
\end{aligned}
$$

$$
\begin{aligned}
Q & =t_{Q} \times Q m / 2 c \\
& =254 \times 31 /(2 \times 119) \\
& =34 \text { veh. }
\end{aligned}
$$




\subsection{IMPLEMENTATION OF HYDRAULIC FOOTPATH:}

3.4.1 Calculation for service volume after implementing hydraulic footpath at signalized intersection:

-Service volume at $7.5 \mathrm{~m}$ width of road:

- Width of road $=7.5 \mathrm{~m}$

- Load factor $=0.3$

...(ref. from HCM 2000)

- Population for city $=24$ lakh

- Peak hour factor:

$\mathrm{PHF}=V / 4 \times \mathrm{V} 15=5500 / 4 \times 1420=0.96$

- Hourly Volume $=5500 \mathrm{v} / \mathrm{hr}$

...(from nomograph chart)

- Peak hour factor $=1.21$

...(Depend on population)

- $G / C$ ratio $=3.1 / 119=0.26$

Therefore, service volume $=$ Vehicle volume per hour

Adjustment factor $\times$

Peak hour factor $x$

$G / C$ ratio

$=5500 \times 1.25 \times 1.21 \times 0.26$

$=2162 \mathrm{VPH}$

3.4.2 Calculation for Queue length after implementing hydraulic footpath:

1) Nara Road:
- Service Volume $=1773 \mathrm{VPH}$

- Service Rate $=1242 \mathrm{VPH}$ ....(Assume)

- $\quad$ Arrival Rate $=1320 \mathrm{VPH}$ ....(Assume)

$$
\begin{aligned}
t_{Q} & =\left(C-C_{r}\right) \times t / C-V \\
& =(1773-1242) \times 0.023 / 1773-1320 \\
& =0.026 \mathrm{hr} .=97 \mathrm{sec} .
\end{aligned}
$$

$$
\begin{aligned}
Q_{m} & =\mathrm{V} \times r / 3600 \\
& =1320 \times 84 / 3600 \\
& =31 \mathrm{veh}
\end{aligned}
$$

$$
\begin{aligned}
\mathrm{Q} & =t_{Q} \times Q m / 2 c \\
& =97 \times 31 / 2 \times 119=13 \text { veh. }
\end{aligned}
$$

\subsection{CALCULATION OF FOOTPATH AND PEDESTRIAN:}

\subsubsection{Data analysis for pedestrian traffic:}

- Width of footpath $=1.2 \mathrm{~m}$

- Standard width of footpath for urban street $=1.5 \mathrm{~m}$

...(recommended by IRC table 11.39 . ref.47)

- Capacity of footpath in $1.5 \mathrm{~m}$ width of footpath $=800 \mathrm{P} / \mathrm{hr}$.

..... (Given in IRC table. ref. 47)

- Capacity of footpath in $1.2 \mathrm{~m}$ width of footpath is

$$
\begin{aligned}
& 800 / 1.5=? / 1.2 \\
= & 800 \times 1.2 / 1.5 \\
= & 640 \mathrm{p} / \mathrm{hr} .
\end{aligned}
$$


Therefore, Data analysis for survey is 220 persons are traveled on each footpath.

.....( data analysis after surveying)

\subsubsection{Loading calculation for footpath:}

A) For pedestrian:

- Width of footpath $=1.2 \mathrm{~m}$

- Length of footpath $=10 \mathrm{~m}$

- Area of footpath $=12 \mathrm{~m}^{2}$

- Minimum Average surface required in pedestrian $=0.085 \mathrm{~m}$

- No. of pedestrian in footpath surface

$$
\begin{aligned}
& =12 / 0.085 \\
& =142 \mathrm{No} .
\end{aligned}
$$

- Average weight of presence per head $=60 \mathrm{~kg} / \mathrm{head}$

$$
\text { ....(ref. for WHO data analysis) }
$$

- Total weight of pedestrian in footpath surface

$$
\begin{aligned}
= & \text { No. of person's } \times \\
& \text { wt. of person } \\
= & 142 \times 60 \\
= & 8520 \mathrm{~kg}
\end{aligned}
$$

- 8520 per $12 \mathrm{~m}^{2}$ area of footpath surface

$$
\begin{aligned}
& =8520 / 12 \\
& =710 \mathrm{~kg} / \mathrm{m}^{2}
\end{aligned}
$$

B) For vehicles:

- Average of all vehichle

$$
\text { = 4-wheeler } / \text { Passenger/Ambulance }
$$

- Dimension of vehicle (Area) $=2.40 \mathrm{~m}^{2}$

(ref. from text book)
- Weight of vehicle $(\mathrm{kg})=1200 \mathrm{~kg}$

(ref. from text book)

- $\quad$ No. of vehicle $=$ Area of footpath surface

/ Area of vehicle required

$=5$ No. of vehicles

- Average weight of vehicle include in passenger

= weight of vehicle + passenger weight $x$ No. of person's

$$
=1200+60 \times 9
$$

$=1740 \mathrm{~kg}$

Therefore, weight of vehicle on footpath surface $=$ weight of vehicle $\times$ No. of vehicle

$$
\begin{aligned}
& =1740 \times 5 \\
& =8700 \mathrm{~kg} / 12 \mathrm{~m}^{2} \\
& =725 \mathrm{~kg} / \mathrm{m}^{2} .
\end{aligned}
$$

\subsubsection{Loading capacity of footpath surface:}

- Total weight of vehicle on footpath surface $=725 \mathrm{~kg} / \mathrm{m}^{2}$

$$
=0.0725 \mathrm{~kg} / \mathrm{cm}^{2}
$$

- Total weight of pedestrian on footpath surface $=710 \mathrm{~kg} / \mathrm{m}^{2}$

$$
=0.072 \mathrm{~kg} / \mathrm{cm}^{2}
$$

- Provided the metal sheet on footpath surface 1) Type - Steel metal sheet 

2) Tolerance - $6327 \mathrm{~kg} / \mathrm{cm}^{2}$

(TensileStrength)

$$
-2812 \mathrm{~kg} / \mathrm{cm}^{2}
$$

(Yield Strength)

- Provided the hydraulic machine below the footpath which lift footpath up and down:
a) Type: Fixed Displacement Pump
b) Model: F-12
c) Pressure: $6000 \mathrm{PSI}=422 \mathrm{~kg} / \mathrm{cm}^{2}$
d) Speed: $2290 \mathrm{RPM}$
e) Flow rate: 240 LPM
f) Compacted and Light weight
g) Thermal Shock resistance

\section{RESULT}

\section{Traffic analyzed at Bhim square on normal footpath} and after implementing hydraulic footpath:

\begin{tabular}{|c|c|c|c|c|c|c|c|c|}
\hline \multirow[t]{2}{*}{ Sr. No. } & \multirow{2}{*}{$\begin{array}{l}\text { Road } \\
\text { Name }\end{array}$} & \multicolumn{3}{|c|}{$6.2 \mathrm{~m}$ width of road } & \multicolumn{3}{|c|}{$7.5 \mathrm{~m}$ width of road } & \multirow{2}{*}{$\begin{array}{c}\begin{array}{l}\text { Reduction } \\
\text { of queue } \\
\text { length }\end{array} \\
\%\end{array}$} \\
\hline & & $t_{Q}$ & $Q_{m}$ & $Q$ & $t_{Q}$ & $Q_{m}$ & $Q$ & \\
\hline 1. & Nara road & 254 & 31 & 34 & 97 & 31 & 13 & $62 \%$ \\
\hline 2. & $\begin{array}{l}\text { Indora } \\
\text { road }\end{array}$ & 250 & 36 & 37 & 99 & 36 & 15 & $60 \%$ \\
\hline 3. & WCL road & 220 & 28 & 30 & 87 & 28 & 13 & $57 \%$ \\
\hline 4. & $\begin{array}{l}\text { Pathanlar } \\
\text { road }\end{array}$ & 224 & 23 & 26 & 87 & 23 & 10 & $62 \%$ \\
\hline
\end{tabular}

\section{CONCLUSION}

The present study is conducted for the hydraulic footpath at signalized intersection, which effective management for high degree of accuracy to be applicable for traffic flow with wider traffic volume from each intersection. A new mechanical concept is discussed to design footpath, which help of hydraulic mechanism in footpath surface at signalized intersection of roads. It finds wide application in road work planning and design. To understand the significant effects by the traffic management at intersection as well as pedestrian noncompliance and pedestrian vehicular interaction this model are developed. The study is conducted on important parameters such as Reduce Queue length, minimize the formation of platoons, increase service rate and provide extra space for maneuverings the traffic in emergency situation.

\section{REFERENCES}

[1]. Sunil Kumar v and J. Ranjitha (2013). "Improvement of Traffic Operations In Congested Signalized Intersections", International Journal of Engineering Research \& Technology (IJERT) ISSN: 2278-0181.

[2]. Kadali BR and Vedagiri P (2013). "Investigated the behaviour of pedestrian road crossing at the uncontrolled midblock location in India under mixed traffic condition using multiple linear regressions (MLR) technique”, European Transport ISSN 1825-3997.

[3]. Zhang X et al. (2013). "Investigated the effects of pedestrian green time, crosswalk length and pedestrian crossing direction on pedestrian walking speed at signalized crosswalk", Proceedings of the Eastern Asia Society for Transportation Studies, Vol.9. 
[4]. Dein Shaw, Jyun-Jhe $\mathrm{Yu}$ and Cheng Chieh (2013). "Design of a Hydraulic Motor System Driven by Compressed Air", Energies ISSN 19961073.

[5]. HAO Yanxi and YANG Xiaoguang*(2013). "Research on the Delay in Signalized Intersection with left turn special phase"13th COTA International Conference of Transportation Professionals, published by Elsevier Ltd: 2211 - 2218.

[6]. K.Vidhya and A.Bazila Banu (2014). "Density Based Traffic Signal System", International Journal of Innovative Research in Science, Engineering and Technology ISSN: 2319 - 8753.

[7]. Ashwini Basavaraju, Senhalata Doddigarla, Navitha Naidu, and Shruti Malgatti (2014). "Vehicle Density Sensor System to Manage Traffic", International Journal of Research in Engineering and Technology ISSN: 2319-1163.

[8]. Narendra M. Hatwar and Prof.V. K. Gajghate (2014). "Impact of New Public Transportation System in Nagpur City", International Journal of Engineering Research and Development ISSN: 2278-067X.

[9]. P. Prema and Dr. A. Murugan (2015). "Intelligent traffic light control using wireless sensor networks with prioritize emergency vehicles"', International Journal OF Engineering Sciences \& Management Research ISSN 23496193.

[10]. Gowri Asaithambi, Manu O. Kuttan1 and Sarath Chandra (2016) "Pedestrian road crossing behaviour under mixed traffic conditions", Springer International Publishing Switzerland DOI 10.1007/s40890-016-0018-5.

[11]. Basil David Daniel and Siti Naquiyah Mohamad Nor (2016). "Pedestrian Footpath Level of Service (FOOT-LOS) Model for Johor Bahru", MATEC Web of Conferences 47, 03006.

[12]. Miss. Aishwarya B. Shinde, Miss. Pranita B. Daphal and Miss. Pratiksha S. Nilange (2016).
"Design and Fabrication of Mechanical Lift for Transportation", Global Research and Development Journal for Engineering ISSN: 2455-5703.

[13]. Syedah Tabish1 Er. Munish Kumar (2017). "Research Paper on study Of Pedestrian Crossing Behaviour, Analysis of Intersection”, International Journal of Latest Research in Science and Technology ISSN:2278-5299.

[14].Mr. Virendra P. Patill and Ms. Shweta D. Bhasme (2019). "A Review on Design and Analysis of Hydraulic Powerpack and Pumps", International Research Journal of Engineering and Technology e-ISSN: 2395-0056.

[15]. C.N.Gawali, D.R.Naxin and S.S.Kapgate .(2019) "Comparative Study of Signalized Intersection and Rotary for Effective Traffic Management", International Journal of Management, Technology And Engineering, Volume IX, Issue I, ISSN NO : 2249-7455.

\section{Cite this article as :}

Prof. Chetan N. Gawali, Amit R. Bhongade, Amit M. Ramteke, Nilesh G. Landge, Prafull P. Shende Author, Sagar S. Modak, "Effective Traffic Management System By Using Hydraulic Footpath", International Journal of Scientific Research in Science and Technology (IJSRST), Online ISSN : 2395-602X, Print ISSN : 2395-6011, Volume 7 Issue 3, pp. 305-313, May-June 2020. Available at doi : https://doi.org/10.32628/IJSRST207346

Journal URL : http://ijsrst.com/IJSRST207346 